[seção $A$ vista]

\title{
NOVA CARTOGRAFIA SOCIAL COMO INSTRUMENTO DE LUTA POLÍTICA
}

\section{NUEVA CARTOGRAFÍA SOCIAL COMO INSTRUMENTO DE LUCHA POLÍTICA}

\author{
Camila A. Baeza, ${ }^{1}$ Rejane C. M. de Almeida ${ }^{2}$ \\ ${ }^{1}$ Programa de pós-graduação em Estudos de Cultura e Território - Universidade \\ Federal do Tocantins (UFT) \\ 2 Programa de pós-graduação em Estudos de Cultura e Território - Universidade \\ Federal do Tocantins (UFT) \\ Contato principal: rejmedeiros@uft.edu.br
}

\begin{abstract}
Resumo: $O$ mapeamento social é resultado de um processo de colaboração entre as/os moradoras/es do acampamento Ilha Verde e pesquisadoras/es da Universidade Federal do Tocantins, Núcleo de Pesquisa e Extensão em Saberes e Práticas Agroecológicas (NEUZA) em conjunto com discentes e docentes do Programa de Pós-Graduação em Estudos de Cultura e Território (PPGCult), assim como de docentes e discentes do curso de Educação do Campo (LEDOC) que estavam com atividades no tempo comunidade. O mapa é a síntese do registro dos elementos culturais do território Ilha Verde e suas territorialidades. Em abril de 2019 foi realizada uma oficina com a comunidade no qual disponibilizamos papéis brancos, A4 e lápis coloridos, para elaboração do mapa situacional. Durante a atividade, foram desenhadas as casas em conjunto com os elementos que se encontram ao seu entorno. A cada desenho de uma casa, ocorria o registro com os nomes de quem pertencia, fazendo especial destaque aos seus nomes em suas respectivas casas. $A$ água (lago) foi o principal elemento registrado pela comunidade.
\end{abstract}

Resumen: El mapeo social es el resultado de un proceso de colaboración entre los residentes del campamento Ilha Verde e investigadores de la Universidad Federal de Tocantins, Núcleo de Investigación y Extensión en Saberes y Prácticas Agroecológicas (NEUZA) junto con estudiantes y profesores del Programa de Posgrado en Estudios de Cultura y Territorio (PPGCult), así como profesores y estudiantes del curso de Educación del Campo (LEDOC) que estuvieron activos en el tiempo de la comunidad. El mapa es la síntesis del registro de los elementos culturales del territorio de la Isla Verde y sus territorialidades. En abril de 2019 se celebró un taller con la comunidad en el que se facilitaron libros blancos, A4 y lápices de colores para la elaboración del mapa de situación. Durante la actividad, las casas fueron diseñadas junto con los elementos que las rodean. Cada dibujo de una casa se registraba con los nombres de los que pertenecían, haciendo 
especial hincapié en sus nombres en sus respectivas casas. El agua (lago) fue el principal elemento registrado por la comunidad.

\section{Introdução}

A construção da Cartografia Social realizada pelos Acampados do "Ilha Verde" está relacionada com a história e memória das/os atingidas/os por barragens, como registro de sua identidade coletiva e de defesa do território. Como Cartografia social, Almeida (2013), define como sendo a Nova cartografia social, pois possibilita produções cartográficas com uma maior atuação das populações que habitam o território a ser mapeado. Buscam estratégias legais para defendê-la, encontrando na Nova cartografia social um instrumento jurídico com o qual possam lutar pelos seus direitos territoriais e culturais. São Culturais, porque segundo Almeida (2013), os grupos sociais se unem através de projetos de mapeamento socioparticipativo, como cultura no sentido de traços ou tradições étnicas. Cultura e identidade coletiva se tornam consciência territorial e a defesa da mesma.

O mapa realizado no Acampamento resultou de um processo de colaboração entre as/os moradoras/es do acampamento "llha Verde", o Núcleo de Pesquisa e Extensão em Saberes e Práticas Agroecológicas (NEUZA) em conjunto com diferentes alunos do PPGCULT e de alunas/os do curso de Educação do campo. Os desenhos do território e suas territorialidades foram registrados em um papel A4 branco onde as/os moradoras/es fizeram o mapa situacional.

A representação cartográfica na figura 1 caracteriza 0 território, as territorialidades do processo de territorialização constituídos pelos acampados nos deslocamentos sofridos pela expulsão dos seus territórios provocados pela Usina Hidrelétrica de Estreito, Maranhão. O exercício da construção do mapa antecede os registros das memórias e histórias de vida que possibilitaram o registro cartográfico.

Figura 1 Oficina de Mapa Social 


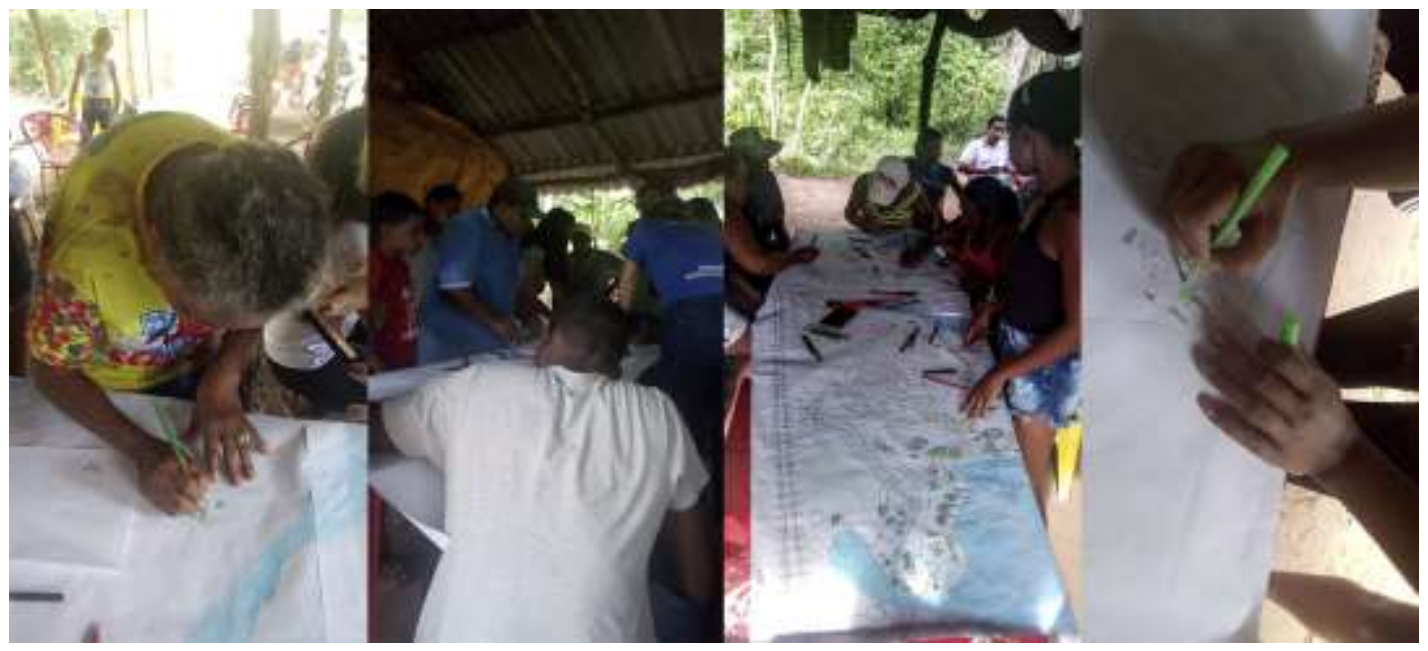

Fonte: BAEZA, Camila, Abril de 2019.

Figura 2: Croqui do mapa Social do Acampamento Ilha Verde 


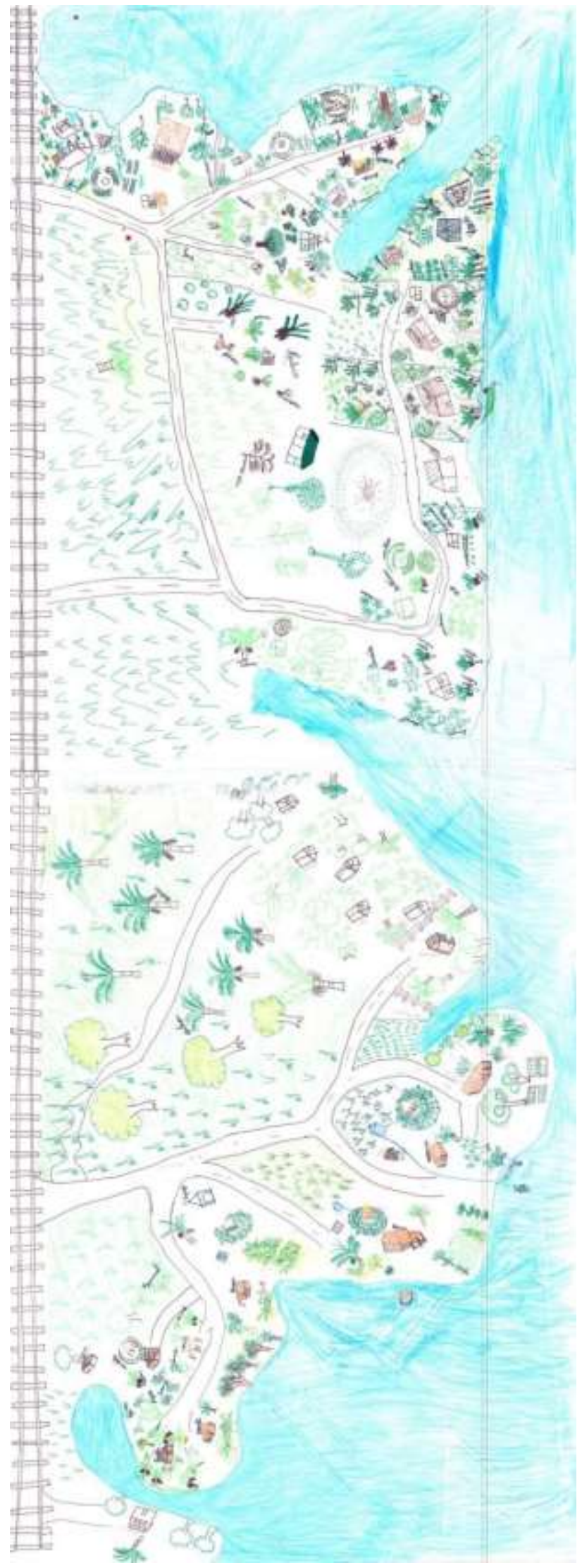

Fonte: Mapa social, UFT/PPGCULT/ NEUZA, 2019. 
O produto gerado pela Cartografia Social Figura 2 permitiu a comunidade marcar no papel as práticas realizadas pelas famílias. Cada família tinha uma casa feita de madeira e palha onde as cozinhas em geral se encontravam por fora das mesmas. Ao redor das casas que eram soltas estavam os pequenos animais e as produções agroecológicas. O acampamento tinha espaços de encontro em comum. São territorialidades construídas no processo de reterritorialização.

Consideramos a territorialidade como [...] fator de identificação, defesa e força, mesmo em se tratando de apropriações temporárias dos recursos naturais, por grupos sociais classificados muitas vezes como "nômades" e "itinerantes". Laços solidários e de ajuda mútua informam um conjunto de regras [...] (ALMEIDA, 2008. p. 29). Nesse sentido é que a territorialização, o uso em comum de certos elementos naturais como o lago tanto como a agrupação das famílias ao estabelecer a ocupação nas terras e uso do território, prevalece suas práticas anteriores, na construção do novo território.

Podemos ver no mapa, os elementos em comum, tanto de moradia, como de existência, em relação com a natureza e a luta que realizaram essas famílias para se estabelecer como acampamento no espaço demarcado por eles e elas. Há a repetição de elementos como hortas, casas, galinhas, árvores frutíferas, botes para pesca, como também o uso dos recursos naturais, principalmente o lago. Outro elemento de destaque no mapa são as palmeiras de cocô babaçu, elas aparecem repetidamente.

\section{Referências}

ALMEIDA, A. W. B. de. (2008). Antropologia dos Arquivos da Amazônia. Rio de Janeiro: Casa 8/Fundação Universidade do Amazonas.

ALMEIDA, A. W. B., ALMEIDA F. J. E. (2013). Povos e comunidades tradicionais. Nova cartografia social. Manaus. 